\title{
A study on Passengers Perspective towards in-flight food delivery and waste collection services
}

\author{
Koh Mei Shin ${ }^{1}$, Yip Kin Hon ${ }^{1}$, and Salini Devi Rajendran ${ }^{1 *}$ \\ ${ }^{1}$ Faculty of Business and Information Science, UCSI University, Jalan Menara Gading, 56000 Cheras, Kuala Lumpur, Malaysia.
}

\begin{abstract}
The quality of the direct airline services especially food delivery and waste collection services can affect the passenger's impression toward the airlines. This study mainly focuses on determine Malaysian passengers' characteristics in selecting flight services and identifying the perception of Malaysian passengers regarding in-flight food delivery service performance. The data was gathered through questionnaires from 405 Malaysian passengers from Malaysia's main international airport, Kuala Lumpur International Airport (KLIA). Software of IBM SPSS version 22 is used to analyze the collected data. This study contributes the knowledge on Malaysian passenger's opinion regarding in-flight food delivery service and explores the areas that need for improvement. The findings of this result could be considered for the airline companies which trying figure out a way to maintain and improve quality of in-flight food service.
\end{abstract}

\section{INTRODUCTION}

Overall service efficiency of the in-flight food delivery procedure has always been concerns for the flight passengers [1]. Sometimes, some passengers in the flight would have to wait longer for the in-flight food as the flight attendants are serving some rows first [1]. Depending on the rows that the passengers are seated, the waiting time can be different [1]. According to a research, more than $47 \%$ of the respondents stated that they had to wait more than 10 minutes on average for the in-flight food delivery services after it started [1]. Long waiting time for inflight food service resulted in negative perception of passengers towards airline companies especially the passengers on short haul flight [1]. Passengers found that the meal that they wanted to order was no longer available as they were among the last passenger to be served [1].

On the other hand, the passengers also concern about the degree of convenience for passengers to move or pass through the aisle while in-flight food are being delivered by the flight attendants. This is because the serving trolley always blocking the aisle during the in-flight food distribution process [1]. For safety reasons, the wheels of the serving trolley have to be blocked upon each stop and released again for each continuing serving journey [2]. Passengers are frequently blocked by a trolley in the aisle when wanting to go to the lavatories or when accompanying a child. It is very difficult for passengers who want to use the lavatory to walk through the aisle as the serving trolley is blocking their way [1]. Passengers cannot move freely in the aisle when the cabin servants are delivering in-flight foods [3]. Besides, passengers are complaining that their personal privacy is being disturbed when the flight attendants are serving other passengers in the same or nearby rows where they are seated [1]. As the population nowadays is getting taller and bigger, seats in the economy class cabin are also becoming small or narrow. Therefore, people are feeling less comfortable in their seats, transforming as agreeable flight into a painful and stressful experience [4]. Many passengers felt that they were disturbed by the serving process but they wish to rest at their seats without being bothered [1]. The situation is worse if the passenger is seated in the aisle or middle seat of the row since the service interaction with other passengers will have to go through his or her space [1].

Furthermore, flight passengers are concerning on the flexibility of in-flight food delivery service. For example, in a long-haul route, in-flight meal service is generally provided in the order of aperitif service, the 1st meal service, refreshment drink, and the second meal service according to a fixed time schedule [5]. However, the passengers are willing to be served at their own leisure instead of at a fixed time period [1]. Passengers felt that they were forced to eat at a certain time period of inflight food serving even though they prefer to have their meal earlier or later [1]. All of these in-flight service inefficiencies can be overcome by selecting the right suppliers with the appropriate facilities and experience for the job.

Therefore, this study mainly contributes to passengers perspectives towards in-flight food delivery service. Hence, the information obtained from this survey study can be applied this to help aviation service providers to make improvements on their current services or develop a new strategic for in-flight food delivery process. 


\section{METHODOLOGY}

This study is a hypothesis testing study using quantitative approach. In this study, data collected will be converted into numerical form to identify the relationship between independent variables (customer's' perspective) and dependent variable (in-flight food delivery service). The unit of analysis is targeted at individual of people and the study will be conducted by multiple cross-sectional studies at a single moment in time.

\subsection{Hypotheses}

H1: There is a significant relationship between overall service efficiency and Malaysian passengers' perspectives towards in-flight food delivery service.

$\mathrm{H} 2$ : There is a significant relationship between convenience for passenger and Malaysian passengers' perspectives towards in-flight food delivery service.

H3: There is a significant relationship between personal privacy and Malaysian passengers' perspectives towards in-flight food delivery service.

H4: There is a significant relationship between flexibility of service and Malaysian passengers' perspectives towards in-flight food delivery service.

\subsection{Location of study}

The study will be conducted at the major airport in Kuala Lumpur which is Kuala Lumpur International Airport (KLIA) (IATA: KUL). People who arrives airport are assumed to have a fresh experience of in-flight meal delivery service provided by airline companies.

\subsection{Target Population and Sampling Technique}

Malaysian flight passengers are the targeted population in this study and the questionnaire will be distributed to the flight passengers at Kuala Lumpur International Airport (KLIA) (IATA: KUL). The non-probability sampling method is conducted due to population size is unknown. Data collect will be based on convenience sampling.

\subsection{Variable Measurement}

The questionnaire will be consisting three sections. In section 1, personal data information and demographic characteristics of respondents such as gender, age, academic level, income level, race, characteristics in selecting flight service will be presented and determined by using the nominal, ordinal and ratio scale.

In section 2 is divided into four parts, which are part $\mathrm{A}, \mathrm{B}, \mathrm{C}$ and $\mathrm{D}$, to determine Malaysian passengers' perspective on in-flight food delivery service in terms of overall service efficiency, convenience for passengers, personal privacy and flexibility of service.

In section 3, dependent variable of Malaysian passengers' perception on in-flight food delivery services will be examined by using the Likert Scales with 5points from first point scale, strongly disagree, to the fifth point scale; strongly agree with the questions or statements. The quantitative data will be collected by using the structured techniques of paper questionnaires.

\subsection{Data Collection}

This study is adopted by self-administered which is distributing the paper questionnaire to targeted sample personally. The respondents will be given sufficient time to answer the questionnaire to prevent the inaccurate answer due to time constraint imposed.

\subsection{Pilot Test}

Before conducting the real distribution of survey questionnaires to target respondents, there is a pilot test with 32 respondents that represent the passengers of air flight service within the intended sample. The purpose of having pilot test is to find out the appropriateness and applicability of the scale to study. It is also to make sure that the questions are understandable by the respondents, and also to find out how long a respondent takes to complete the survey in real time.

\subsection{Data Analysis Method}

In this study, the data analysis will be conducted by using software of IBM SPSS version 22 and with the help of Microsoft Office Excel 2016. The data collected by online questionnaire via Google Form will then converted into spreadsheet and Microsoft Excel 2016 in order to show the data clearly.

The main statistical analysis is descriptive statistics which examine the demographic characteristics of the respondents and multiple regression analysis will be performed to identify the variables that influenced upon in-flight food delivery service.

\subsubsection{Normality Test}

A normality test is used to determine whether sample data has been drawn from a normally distributed population (within some tolerance). For normality test, data collected will be tested by using KolmogorovSmirnov test, Skewness and Kurtosis test and ShapiroWilk test $[6,7]$. Skewness and Kurtosis test show the data distribution pattern. A $100 \%$ normal distribution has skewness and kurtosis values of zero. Skewness indicates a skewed distribution. A positive value shows a positively skewed graph, whereas a negative value shows a negative skew. Kurtosis shows the height of the distribution (high or low). A positive kurtosis value shows a high distribution curve and a negative kurtosis value shows a low distribution curve. For a data to be 
normally distributed, the skewness and kurtosis value should be in the range of -1.96 to +1.96 .

The Shapiro-Wilk test is based on the correlation between the data and the corresponding normal scores and provides better power than the Kolmogorov-Smirnov test. Power is the most frequent measure of the value of a test for normality, the ability to detect whether a sample comes from a non-normal distribution.

\subsubsection{Reliability Test}

Reliability analysis will be conducted by using Cronbach's alpha method to verify the internal consistency of the measurement scales to be used in this study [8-10]. Cronbach's alpha method is used to identify the correlation value between scores for each item in the test and the total score for all items in the test, which is also known as the text index score. Through this method, items with high correlation values with the text index score have high reliability whereas items with low correlation values have low reliability and will be discarded from the test.

\subsubsection{Descriptive Analysis}

Descriptive statistics is used to perform the frequency distribution of study. Frequency distribution displays the score value of a frequency occurrence. It can be displayed in various forms such as tabular form, graphic forms according to the type of variables. For instance, histograms, polygons, pie charts and bar charts are several forms to perform frequency distribution.

\subsubsection{Multiple Regression}

The multiple regression test is used in this study to identify change in the factors [11]. The factors include overall efficiency, convenience for passengers, personal privacy and flexibility of service (independent variables), which contributes to change in passengers' perception on in-flight food delivery service (dependent variable).

\section{RESULT AND DISCUSSION}

\subsection{Pilot test}

The questionnaires were answered by 32 respondents in total for the pilot test. All the questionnaires were distributed to respondents through online Google Form. Table 1 shows the Cronbach's alpha data of 0.977 has met the basic requirement of at least 0.7 as recommended by Nunnally [12].

\subsubsection{Reliability Analysis}

Reliability of the instrument was assessed to determine internal consistency. This study instrument is satisfactory as it is greater than 0.65 (alpha coefficient $=0.977$ ) [13] Thus, the study result indicates a high level of reliability.

Table 1. Cronbach's alpha statistics

\begin{tabular}{ccc}
\hline Cronbach's Alpha & Cronbach's Alpha Based on Standardized Items & N of Items \\
\hline .977 & .978 & 32 \\
\hline
\end{tabular}

Standard deviation is a mathematical tool that helps to assess the distance that the values are spread above and below the mean. A low standard deviation shows that the data are clustered closely around the mean or expected value, $\mu$, thus it is more reliable. Conversely, a high standard deviation indicates that the data is widely spread and is less reliable. Based on Table 2, the standard deviation value is 26.325 . Thus, the study result is satisfactory and indicates an acceptable level of reliability.

Table 2. Mean, Variance and Standard Deviation of Pilot Test

\begin{tabular}{cccc}
\hline Mean & Variance & Std. Deviation & N of Items \\
\hline 95.14 & 693.004 & 26.325 & 32 \\
\hline
\end{tabular}

In this pilot test, the distribution of data is normal because both the skewness $(-0.258)$ and kurtosis $(-0.135)$ values are within the distribution range $(-1.96$ to +1.96$)$. Besides that, for Kolmogorov-Smirnov and the ShapiroWilk tests, data is normally distributed if the tests are insignificant (the tests will be insignificant if $\mathrm{p}>0.05$ ). The results of both tests are Kolmogorov-Smirnov (Sig. $=0.200)$ and Shapiro-Wilk (Sig. $=0.792)$, which is insignificant and thus the data is normally distributed.
Based on the data collected, the demographic data of respondents was constructed. The study questionnaires were answered by 405 respondents. Table 3 shows there were 197 (48.6\%) male and 208 (51.4\%) female and all the respondents are Malaysian. Most of the respondents are age between 21 and 30 years old about $44.2 \%$. Majority of the respondents are Chinese about $65.9 \%$. The respondent with diploma and degree are $27.9 \%$ and $52.6 \%$ respectively. The incomes per month of most of the respondents are below RM999 about $40.5 \%$ and above RM2500 about 29.9\%.

\subsection{Descriptive Analysis}

Table 3. Demographic data of respondents

\begin{tabular}{lccc}
\hline Items & Category & Frequency $(\mathrm{n})$ & Percentage $(\%)$ \\
\hline Gender & Male & 197 & 48.6 \\
& Female & 208 & 51.4 \\
\hline
\end{tabular}




\begin{tabular}{lccc}
\hline Nationality & Malaysian & 405 & 100 \\
\hline Age (years old) & 20 and below & 42 & 10.4 \\
& $21-30$ & 179 & 44.2 \\
& $31-40$ & 109 & 26.9 \\
& $41-50$ & 49 & 12.1 \\
& 50 and above & 26 & 6.4 \\
\hline Ethic & Malay & 75 & 18.5 \\
& Chinese & 267 & 65.9 \\
& Indian & 63 & 15.6 \\
\hline Education level & Primary School & 16 & 4.0 \\
& Secondary School & 59 & 14.6 \\
& Diploma & 113 & 27.9 \\
& Degree & 213 & 52.6 \\
& Postgraduate & 4 & 40.5 \\
\hline Income level (RM) & Below 999 & 164 & 6.2 \\
& $1000-1499$ & 25 & 12.3 \\
& $1500-1999$ & 50 & 11.1 \\
& $2000-2499$ & 45 & 29.9 \\
\hline
\end{tabular}

Figure 1 shows a large portion of the respondents had less than 3 times flight experience within 1 year (287; $70.9 \%$ ). About 49 respondents had 3-5 times flight experience within 1 year (12.1\%), 36 respondents had 610 times flight experience within 1 year $(8.9 \%)$ while 2 respondents had more than 10 times flight experience within 1 year $(0.5 \%)$. However, here were 31 respondents who had not taking any flight within 1 year (7.7\%).

Out of this group of respondents, there were 331 $(81.7 \%)$ with international flight experience while 74

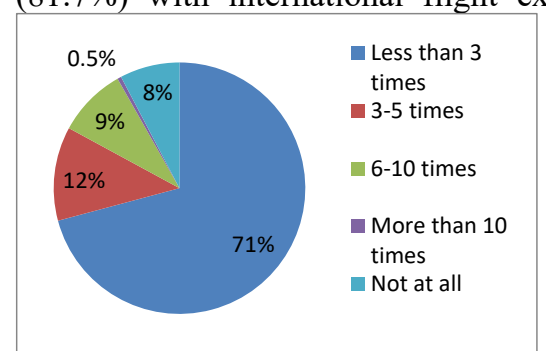

Figure 1. How frequent do you travel by flight (in a year)

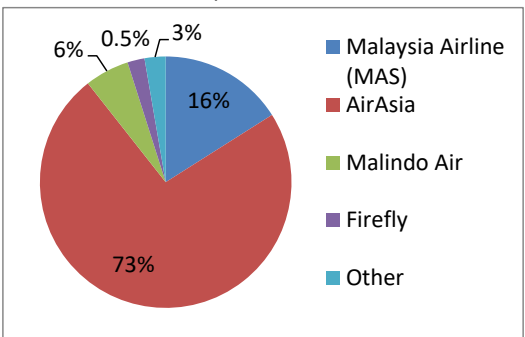

Figure 2. Which airline do you used to travel?
$(18.3 \%)$ with domestic flight experience. Figure 2 shows about 297 (73.3\%) used AirAsia, 65 (16.0\%) used Malaysia Airline (MAS), 23 (5.7\%) used Malindo Air, $11(2.7 \%)$ used other airline company and 9 (15.6\%) respondents used Firefly airline services.

Figure 3 shows majority of the respondents preferred economy class $(373 ; 92.1 \%)$. The remaining $30(7.4 \%)$ respondents preferred business class (or flexi premium) and $2(0.5 \%)$ respondents preferred first class travel service.

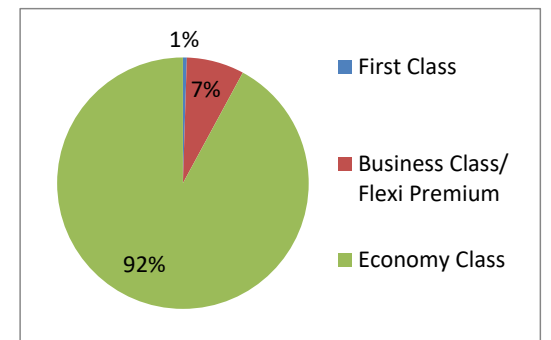

Figure 3. Which travel class would you prefer when choosing an airline service?
In terms of seat selection, there were 304 (75.1\%) respondents not prefer paying extra expenses for seat selection on flight, while 101 (24.9\%) respondents will pay extra expenses for seat selection. Figure 4 shows out of the 101 respondents, 27 (26.7\%) preferred seats that near to window, 25 (24.8\%) preferred quiet area, 19 $(18.8 \%)$ preferred seats that close to the wash room, 13 $(12.9 \%)$ preferred seats with extra leg room, $10(9.9 \%)$ preferred seats that near to the aisle and $7(6.9 \%)$ preferred seats that close to the emergency exit.

Most of the respondents $(376 ; 92.8 \%)$ preferred inflight food delivery service in the cabin, while 29 (7.2\%) respondents do not prefer to have the service. Besides that, among all the respondents, majority of 344 (84.9\%) respondents preferred pre-book in-flight food rather than order on board $(61 ; 15.1 \%)$. Figure 5 shows majority of respondents were waiting for 21-30 minutes (256; $63.2 \%)$. This was followed by 11-20 minutes (80; $19.8 \%), 31-40$ minutes $(57 ; 14.1 \%)$, and $1-10$ minutes $(12 ; 3.0 \%)$.

Figure 6 shows about $292(72.1 \%)$ stated that the inflight food was served 1 time on the aircraft. This was followed by 2 times (86;21.2\%), 3 times (23;5.7\%), 4 times $(3 ; 0.7 \%)$ and only 1 respondents stated that inflight food was served 5 times in the cabin. Last but not least, majority of $365(90.1 \%)$ respondents think that inflight food delivery is necessary on board. However, 40 (9.9\%) respondents do not think that in-flight food delivery is necessary on board. 


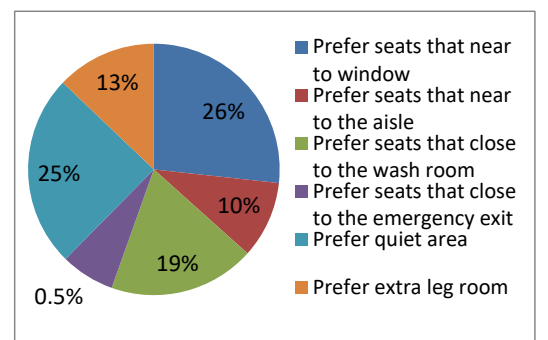

Figure 4. The reason that you would pay for seat selection

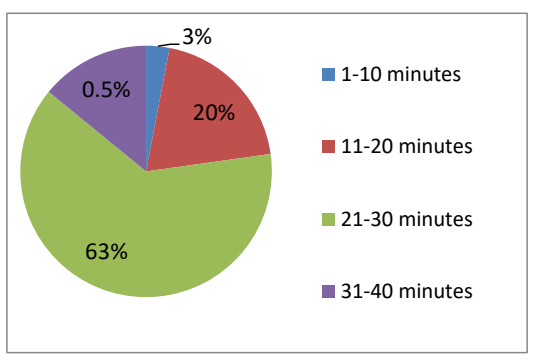

Figure 5. How long you usually wait for your in-flight food on board? (approximately in minutes)

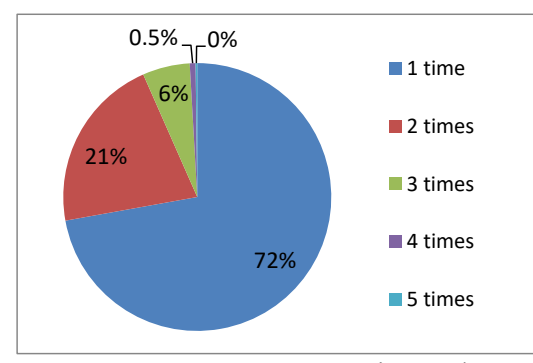

Figure 6. How many times the inflight food was served in your previous experience?

\subsection{Normality Analysis}

Kolmogorov-Smirnov test, Skewness and Kurtosis test and Shapiro-Wilk test are used to conduct the normality test.

\subsubsection{Skewness and kurtosis tests}

For a data to be normally distributed, the skewness and kurtosis value should be in the range of -1.96 to +1.96 . In this case, the distribution of data is normal because both the skewness $(-0.173)$ and kurtosis $(0.014)$ values are within the distribution range.

\subsubsection{Kolmogorov-Smirnov and the Shapiro-Wilk tests}

For the Kolmogorov-Smirnov and the Shapiro-Wilk tests, data is normally distributed if the tests are insignificant (the tests will be insignificant if $p>.05$ ). The $p$-value of both tests here are 0.63 and 0.136 for KolmogorovSmirnov and Shapiro-Wilk tests respectively, which proves that the tests are insignificant and thus the data is normally distributed. The distribution frequency in Figure 7 shows that data is normally distributed because it displays a high distribution in the middle and a low distribution at both the left and right ends.

\subsection{Multiple Regression Analysis}

Data collected from the study questionnaires were then analyses using IBM SPSS software. There were 7 questions for overall service efficiency factor (IV1), 6 questions for convenience for passengers' factor (IV2), 7 questions for passengers' personal privacy (IV3) and 6 questions for flexibility of service factor (IV4). A total number of 26 questions of independent variables were tested to each dependent variable question. Figure 8 shows the method that used to test the multiple regressions.

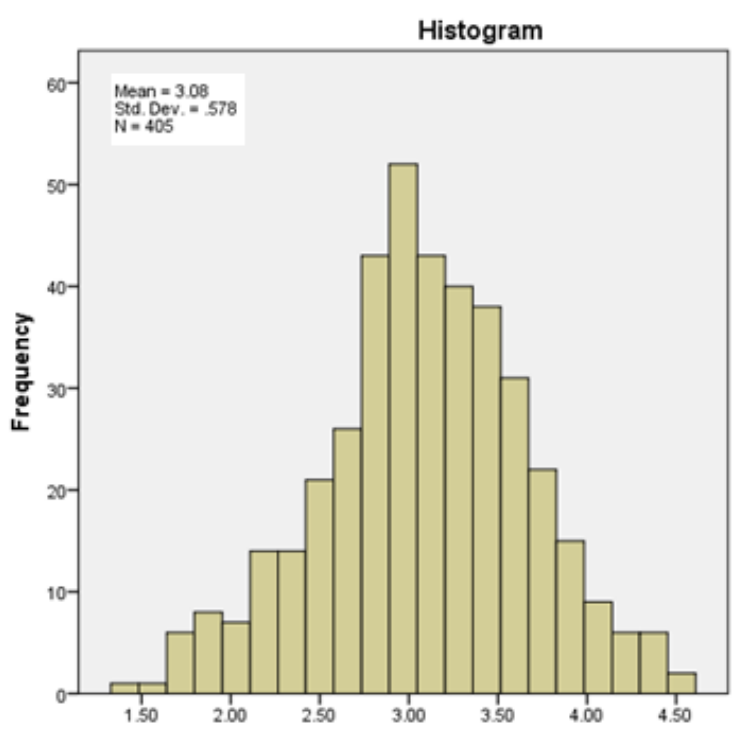

Figure 7. Distribution of frequency

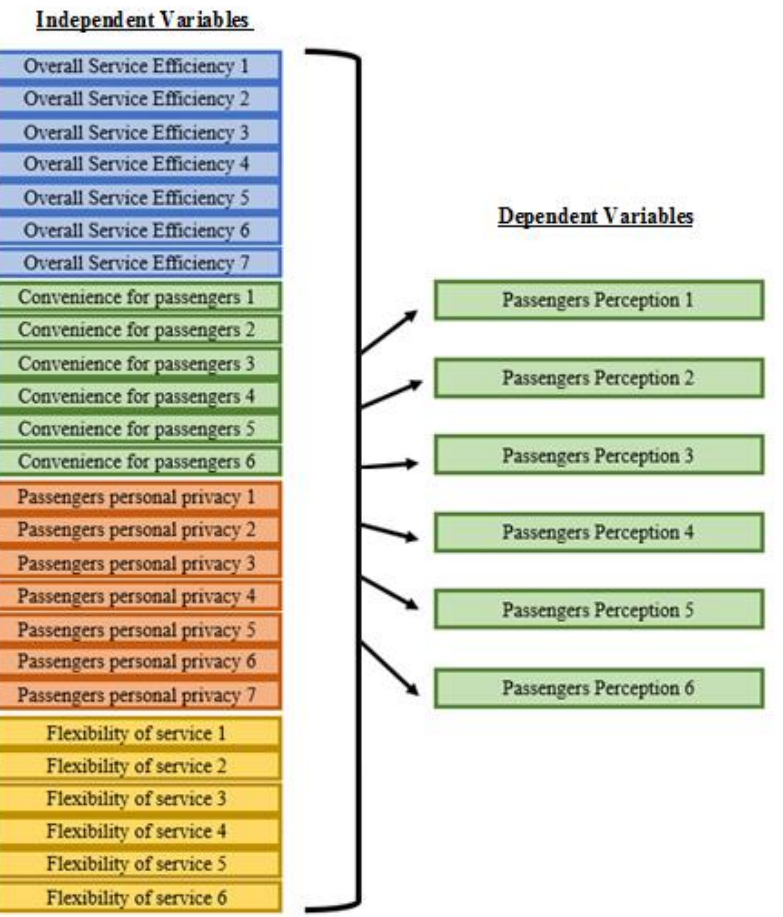

Figure 8. Multiple Regressions Design

The multiple regression analysis results for DV 1 shows that for the study population, the four independent variables, which are passengers personal privacy 7 (P1), 
convenience for passengers 4 (P2), flexibility of service $5(\mathrm{P} 3)$, passengers personal privacy $6(\mathrm{P} 4)$, passengers personal privacy 4 (P5) and overall service efficiency 5 (P6) are main influences on Malaysian passengers perspective towards in-flight food delivery service.

The passengers personal privacy 7 score is the main factor which significantly $(\mathrm{p}<0.05)$ contributes $20.2 \%$ of the variance $\left(\mathrm{R}^{2}=0.202\right)$ in the dependent variable. This means passengers personal privacy 7 (P1) $(\beta=$ $0.164, p<0.05)$ is the main indicator of Malaysian passengers perspective towards in-flight food delivery service. The combination of P1 and P2 $(\beta=0.158, \mathrm{p}<$ $0.05)$ accounts for $7.5 \%$ change $(27.7 \%-20.2 \%)$ of the variance $\left(\mathrm{R}^{2}=0.277\right)$ in Malaysian passengers perspective towards in-flight food delivery service. The combination of P1, P2 and P3 $(\beta=0.141, \mathrm{p}<0.05)$ accounts for $3.7 \%$ change $(31.4 \%-27.7 \%)$ of the variance $\left(\mathrm{R}^{2}=0.314\right)$ in Malaysian passengers perspective towards in-flight food delivery service. However, P4, P5 and P6 independent variables do not contribute much to the change in Malaysian passengers perspective towards in-flight food delivery service because the combination of the P4 $(\beta=0.138, p<0.05), \mathrm{P} 5(\beta=0.119, \mathrm{p}<0.05)$ and P6 $(\beta=0.112, \mathrm{p}<0.05)$ variables with P1, P2 and P3 only accounts for $4.3 \%(35.7 \%-31.4 \%)$ change of the variance $\left(\mathrm{R}^{2}=0.357\right)$ in Malaysian passengers perspective towards in-flight food delivery service.

\subsubsection{Dependent variable 2 (DV2)}

The multiple regression analysis results for DV 2 shows that for the study population, the four independent variables, which are flexibility of service 4 (P1), overall service efficiency 1 (P2), overall service efficiency 2 (P3), passengers personal privacy 5 (P4), convenience for passengers 4 (P5), overall service efficiency 3 (P6) and flexibility of service 1 (P7) are main influences on Malaysian passengers perspective towards in-flight food delivery service.

The flexibility of service 4 score is the main factor which significantly $(\beta=0.160, \mathrm{p}<0.05)$ contributes $26.4 \%$ of the variance $\left(\mathrm{R}^{2}=0.264\right)$ in the dependent variable. This means flexibility of service $4(\mathrm{P} 1)$ is the main indicator of Malaysian passengers perspective towards in-flight food delivery service. The combination of P1 and $\mathrm{P} 2(\beta=0.117, \mathrm{p}<0.05)$ accounts for $9.8 \%$ change $(36.2 \%-26.4 \%)$ of the variance $\left(\mathrm{R}^{2}=0.264\right)$ in Malaysian passengers perspective towards in-flight food delivery service. The combination of P1, P2 and P3 ( $\beta=0.164, \mathrm{p}$ $<0.05)$ accounts for $4.6 \%$ change $(40.8 \%-36.2 \%)$ of the variance $\left(\mathrm{R}^{2}=0.408\right)$ in Malaysian passengers perspective towards in-flight food delivery service. The combination of P1, P2, P3 and P4 $(\beta=0.150, \mathrm{p}<0.05)$ accounts for $3.1 \%$ change $(43.9 \%-40.8 \%)$ of the variance $\left(\mathrm{R}^{2}=0.439\right)$ in Malaysian passengers perspective towards in-flight food delivery service. However, P5, P6 and $\mathrm{P} 7$ independent variables do not contribute much to the change in Malaysian passengers perspective towards in-flight food delivery service because the combination of the P5 $(\beta=0.138, p<0.05)$, P6 $(\beta=0.119, p<0.05)$ and $\mathrm{P} 7(\beta=0.101, \mathrm{p}<0.05)$ variables with $\mathrm{P} 1, \mathrm{P} 2, \mathrm{P} 3$ and P4 only accounts for 3.5\% (47.4\%-43.9\%) change of the variance $\left(\mathrm{R}^{2}=0.474\right)$ in Malaysian passengers perspective towards in-flight food delivery service.

\subsubsection{Dependent variable 3 (DV3)}

The multiple regression analysis results for DV 3 shows that for the study population, the four independent variables, which are flexibility of service 4 (P1), overall service efficiency 1 (P2), flexibility of service 1 (P3), passengers personal privacy $3(\mathrm{P} 4)$, overall service efficiency 5 (P5), overall service efficiency 2 (P6) and passengers personal privacy 7 (P7) are main influences on Malaysian passengers perspective towards in-flight food delivery service.

The flexibility of service 4 score is the main factor which significantly $(\beta=0.186, \mathrm{p}<0.05)$ contributes $25.5 \%$ of the variance $\left(\mathrm{R}^{2}=0.255\right)$ in the dependent variable. This means flexibility of service 4 (P1) is the main indicator of Malaysian passengers perspective towards in-flight food delivery service. The combination of P1 and P2 $(\beta=0.121, \mathrm{p}<0.05)$ accounts for $8.8 \%$ change $(34.3 \%-25.5 \%)$ of the variance $\left(\mathrm{R}^{2}=0.343\right)$ in Malaysian passengers perspective towards in-flight food delivery service. The combination of P1, P2 and P3 $(\beta=0.153, p$ $<0.05)$ accounts for $3.5 \%$ change $(37.8 \%-34.3 \%)$ of the variance $\left(\mathrm{R}^{2}=0.378\right)$ in Malaysian passengers perspective towards in-flight food delivery service. The combination of P1, P2, P3 and P4 $(\beta=0.124, \mathrm{p}<0.05)$ accounts for $2.2 \%$ change $(40.0 \%-37.8 \%)$ of the variance $\left(\mathrm{R}^{2}=0.400\right)$ in Malaysian passengers perspective towards in-flight food delivery service. However, P5, P6 and $\mathrm{P} 7$ independent variables do not contribute much to the change in Malaysian passengers perspective towards in-flight food delivery service because the combination of the P5 $(\beta=0.106, p<0.05)$, P6 $(\beta=0.107, p<0.05)$ and P7 $(\beta=0.103, \mathrm{p}<0.05)$ variables with P1, P2, P3 and $\mathrm{P} 4$ only accounts for $2.6 \%(42.6 \%-40.0 \%)$ change of the variance $\left(\mathrm{R}^{2}=0.426\right)$ in Malaysian passengers perspective towards in-flight food delivery service.

\subsubsection{Dependent variable 4 (DV4)}

The multiple regression analysis results for DV 4 shows that for the study population, the four independent variables, which are flexibility of service $6(\mathrm{P} 1)$, overall service efficiency $1(\mathrm{P} 2)$, passengers personal privacy 7 (P3), flexibility of service 3 (P4), convenience for passengers 1 (P5), flexibility of service 1 (P6) and passengers personal privacy $6(\mathrm{P} 7)$ are main influences on Malaysian passengers perspective towards in-flight food delivery service.

The flexibility of service 6 score is the main factor which significantly $(\beta=0.174, \mathrm{p}<0.05)$ contributes $28.2 \%$ of the variance $\left(\mathrm{R}^{2}=0.282\right)$ in the dependent variable. This means flexibility of service $6(\mathrm{P} 1)$ is the main indicator of Malaysian passengers perspective towards in-flight food delivery service. The combination of P1 and $\mathrm{P} 2(\beta=0.139, \mathrm{p}<0.05)$ accounts for $10.4 \%$ change $(38.6 \%-28.2 \%)$ of the variance $\left(\mathrm{R}^{2}=0.386\right)$ in Malaysian passengers perspective towards in-flight food delivery 
service. The combination of P1, P2 and P3 $(\beta=0.179, \mathrm{p}$ $<0.05)$ accounts for $5.5 \%$ change $(44.1 \%-38.6 \%)$ of the variance $\left(\mathrm{R}^{2}=0.441\right)$ in Malaysian passengers perspective towards in-flight food delivery service. The combination of P1, P2, P3 and P4 $(\beta=0.145, \mathrm{p}<0.05)$ accounts for $2.6 \%$ change $(46.7 \%-44.1 \%)$ of the variance $\left(\mathrm{R}^{2}=0.467\right)$ in Malaysian passengers perspective towards in-flight food delivery service. However, P5, P6 and $\mathrm{P} 7$ independent variables do not contribute much to the change in Malaysian passengers perspective towards in-flight food delivery service because the combination of the P5 $(\beta=0.127, p<0.05)$, P6 $(\beta=0.115, p<0.05)$ and P7 $(\beta=0.091, \mathrm{p}<0.05)$ variables with $\mathrm{P} 1, \mathrm{P} 2, \mathrm{P} 3$ and $\mathrm{P} 4$ only accounts for $2.7 \%(49.4 \%-46.7 \%)$ change of the variance $\left(\mathrm{R}^{2}=0.494\right)$ in Malaysian passengers perspective towards in-flight food delivery service.

\subsubsection{Dependent variable 5 (DV5)}

The multiple regression analysis results for DV 5 shows that for the study population, the four independent variables, which are flexibility of service 6 (P1), passengers personal privacy $6(\mathrm{P} 2)$, passengers personal privacy 1 (P3), passengers personal privacy $3(\mathrm{P} 4)$, convenience for passengers 5 (P5), convenience for passengers 1 (P6) and flexibility of service 3 (P7) are main influences on Malaysian passengers perspective towards in-flight food delivery service.

The flexibility of service 6 score is the main factor which significantly $(\beta=0.175, \mathrm{p}<0.05)$ contributes $28.5 \%$ of the variance $\left(\mathrm{R}^{2}=0.285\right)$ in the dependent variable. This means flexibility of service 6 (P1) is the main indicator of Malaysian passengers perspective towards in-flight food delivery service. The combination of P1 and $\mathrm{P} 2(\beta=0.173, \mathrm{p}<0.05)$ accounts for $7.8 \%$ change $(36.3 \%-28.5 \%)$ of the variance $\left(\mathrm{R}^{2}=0.363\right)$ in Malaysian passengers perspective towards in-flight food delivery service. The combination of P1, P2 and P3 ( $\beta=0.148, \mathrm{p}$ $<0.05)$ accounts for $3.8 \%$ change $(40.1 \%-36.3 \%)$ of the variance $\left(\mathrm{R}^{2}=0.401\right)$ in Malaysian passengers perspective towards in-flight food delivery service. The combination of $\mathrm{P} 1, \mathrm{P} 2, \mathrm{P} 3$ and $\mathrm{P} 4(\beta=0.134, \mathrm{p}<0.05)$ only accounts for $2.7 \%$ change $(42.8 \%-40.1 \%)$ of the variance $\left(\mathrm{R}^{2}=0.428\right)$ in Malaysian passengers perspective towards in-flight food delivery service. However, P5, P6 and P7 independent variables do not contribute much to the change in Malaysian passengers perspective towards in-flight food delivery service because the combination of the P5 $(\beta=0.126, \mathrm{p}<0.05)$, P6 $((\beta=0.102, p<0.05)$ and P7 $(\beta=0.098, p<0.05)$ variables with $\mathrm{P} 1, \mathrm{P} 2, \mathrm{P} 3$ and $\mathrm{P} 4$ only accounts for $3.4 \%$ (46.2\%-42.8\%) change of the variance $\left(\mathrm{R}^{2}=0.462\right)$ in Malaysian passengers perspective towards in-flight food delivery service.

\subsubsection{Dependent variable 6 (DV6)}

The multiple regression analysis results for DV 6 shows that for the study population, the four independent variables, which are flexibility of service 1 (P1), flexibility of service $4(\mathrm{P} 2)$, convenience for passengers
1 (P3), overall service efficiency 7 (P4), convenience for passengers 4 (P5), passengers personal privacy $6(\mathrm{P} 6)$, flexibility of service 2 (P7) and overall service efficiency 5 (P8) are main influences on Malaysian passengers perspective towards in-flight food delivery service.

The flexibility of service 1 score is the main factor which significantly $(\beta=0.191, \mathrm{p}<0.05)$ contributes $30.9 \%$ of the variance $\left(\mathrm{R}^{2}=0.309\right)$ in the dependent variable. This means flexibility of service 1 (P1) is the main indicator of Malaysian passengers perspective towards in-flight food delivery service. The combination of P1 and P2 $(\beta=0.174, \mathrm{p}<0.05)$ accounts for $9.6 \%$ change $(40.5 \%-30.9 \%)$ of the variance $\left(\mathrm{R}^{2}=0.405\right)$ in Malaysian passengers perspective towards in-flight food delivery service. The combination of P1, P2 and P3 ( $\beta=0.114, \mathrm{p}$ $<0.05)$ accounts for $4.1 \%$ change $(44.6 \%-40.5 \%)$ of the variance $\left(\mathrm{R}^{2}=0.446\right)$ in Malaysian passengers perspective towards in-flight food delivery service. The combination of P1, P2, P3 and P4 $(\beta=0.109, \mathrm{p}<0.05)$ only accounts for $1.9 \%$ change $(46.5 \%-44.6 \%)$ of the variance $\left(\mathrm{R}^{2}=0.428\right)$ in Malaysian passengers perspective towards in-flight food delivery service. However, P5, P6, P7 and P8 independent variables do not contribute much to the change in Malaysian passengers perspective towards in-flight food delivery service because the combination of the P5 $(\beta=0.099, \mathrm{p}<$ 0.05), P6 $(\beta=0.104, \mathrm{p}<0.05), \mathrm{P} 7(\beta=0.100, \mathrm{p}<0.05)$ and P8 $(\beta=0.089, \mathrm{p}<0.05)$ variables with $\mathrm{P} 1, \mathrm{P} 2, \mathrm{P} 3$ and $\mathrm{P} 4$ only accounts for $3.5 \%(50.0 \%-46.5 \%)$ change of the variance $\left(\mathrm{R}^{2}=0.500\right)$ in Malaysian passengers perspective towards in-flight food delivery service.

\subsection{Discussion}

The results showed that four factors stated (overall service efficiency, convenience for passenger, passengers personal privacy and service flexibility) were positively significant related to Malaysian passengers perspectives towards in-flight food delivery service. This study revealed that the overall service efficiency, convenience for passenger, passengers personal privacy and service flexibility were able to influence the perception of Malaysian passengers towards in-flight food delivery service. These results support the findings from previous studies conducted by Romli et al. (2016), which found that overall service efficiency, convenience for passenger, passengers personal privacy and service flexibility did influence flight passengers perspective towards in-flight food delivery service [1]. Furthermore, previous studies from JooEun Lee and SeonHee Ko (2016) supported this finding in evaluating how in-flight food service efficiency positively influenced Malaysian passengers perspectives towards in-flight food delivery service [14]. The results also showed that in-flight food service flexibility was perceived as dominant independent variable followed by passenger's personal privacy, overall service efficiency and convenience for passengers. Previous studies found in-flight food service flexibility had a direct impact on passenger's perception [1]. Results from Romli et al. (2016) indicated that some flight passengers are willing to be served the in-flight 
food at their own leisure time instead of at a fixed time [1]. On the other hand, the independent variables of convenience for passenger reveal the least impact on passenger's perception. This study stressed the importance of overall service efficiency, convenience for passenger, passengers personal privacy and service flexibility as critical factors in influencing Malaysian passengers perspectives towards in-flight food delivery service. It is therefore can be used as a reference for airline service company to improve the in-flight food delivery service by focusing on the elements of overall service efficiency, convenience for passenger, passengers personal privacy and service flexibility. Poor overall service efficiency, convenience for passenger, passenger's personal privacy and service flexibility factors may cause negative passengers perception towards the inflight-food delivery service provided by the airline company.

\section{CONCLUSION}

In conclusion, overall service efficiency, convenience for passenger, passengers' personal privacy and service flexibility are important factors on Malaysian passenger's perspectives towards in-flight food delivery service. Failure to consider these three factors may cause negative passengers perspectives towards in-flight food delivery service and eventually bring negative impact to Airline Company. This finding helps airline service provider to have better understanding and knowledge regarding the important elements in overall service efficiency, convenience for passenger, passengers personal privacy and service flexibility which are important factors that may need to consider as important factors in influencing a passengers perspective towards in-flight food delivery service. However, this study is confined in methodology and sample size. The study questionnaires were distributed in Kuala Lumpur International Airport (KLIA) in Malaysia. Thus, this study only represents part of Malaysian air flight passengers.

\section{References}

1. Romli, F.; Rahman, K. and Ishak, F. 2016. In-flight food delivery and waste collection service: the passengers' perspective and potential improvement. AEROTECH VI - Innovation in Aerospace Engineering and Technology. IOP Conf. Series: Materials Science and Engineering 152, 1-7 doi:10.1088/1757-899X/152/1/012040

2. Chen H. T. and Chao, C. C. 2015. Airline choice by passengers from Taiwan and China: A case study of outgoing passengers from Kaohsiung International Airport, Journal of Air Transport
Management
https://doi.org/10.1016/j.jairtraman.2015.08.002.

3. Romli, F. I., Abdul Rahman, K and Ishak, F. D. 2016. In-flight food delivery and waste collection service: the passengers' perspective and potential improvement IOP Conf. Series: Materials Science and Engineering 152012040 doi:10.1088/1757899X/152/1/012040

4. Tan, C. F., Chen, W., Rauterberg G. W. M. and Said M. R. 2013. The Self-Reported Seat Discomfort Survey on Economy Class Aircraft Passenger in the Netherlands. Australian Journal of Basic and Applied Sciences, 7(6), 563-570.

5. Lee, J. E., and Ko, S. H. 2016. Effect of the InFlight Meal Service Quality on the Customer Value and Loyalty. Indian Journal of Science and Technology, 9

(26), DOI:10.17485/ijst/2016/v9i26/97276, July 2016.

6. Sham, R., Wahab, S.N., Anuar, M.M., Tong, W.H. \& Yap, J.T. (2019). Safety Indicator for Taxi Users in Urban Area. International Journal of Supply Chain Management, 8(2), 1035-1041.

7. Wahab, S.N., \& Khong W.L. (2018). Multiple Linear Regression Modelling of Parcels' Distribution Design Factors and online Shopping Customer Satisfaction. International Journal of Modelling in Operations Management, 7(2), 95-110.

8. Teo, A. C., Tan, G. W. H., Cheah, C. M., Ooi, K. B and Yew, K. T. 2012. Can the Demographic and Subjective Norms Influence the Adoption of Mobile Banking?', International Journal of Mobile Communications, 10 (6), 578-597.

9. Wahab, S.N., Sham, R., Hussin, A.A.A, Ismail, S., \& Rajendran, S.D. (2018). Urban Transportation: An Analysis on Bike Sharing Usage in Klang Valley. International Journal of Supply Chain Management, 7(5), 470-476.

10. Wahab, S.N, Olugu, E.U., Lee, W.C., \& Tan, S.Y. (2018). Big data analytics adoption in Malaysia warehousing industry. The 32nd International Business Information Management Association Conference, IBIMA 2018, 2349-2365, 15-16 November, Seville Spain.

11. Chong, J. L., Chong, A. Y. L., Ooi, K. B. and Lin, B. 2011. An empirical analysis of the adoption of $\mathrm{m}$ learning in Malaysia. International Journal of Mobile Communications, 9(1), 1.

12. Nunnally, J. C. 1978. Psychometric Theory. NY: Mcgraw-Hill.

13. Chua, Y. 2012. Mastering Research Methods. Malaysia: McGraw-Hill.

14. Lee, J. E. and Ko, S. H. 2016. Effect of the In-Flight Meal Service Quality on the Customer Value and Loyalty, Indian Journal of Science and Technology, 9 (26), DOI: 10.17485/ijst/2016/v9i26/97276 